\title{
Endocrine Therapy in Early Breast Cancer
}

\author{
Katja Krauss Elmar Stickeler \\ Breast Center, Department of Gynecology and Obstetrics, RWTH University Hospital Aachen, Aachen, Germany
}

\section{Keywords}

Tamoxifen · Aromatase inhibitor · Extended endocrine therapy · Late recurrence - Ovarian function suppression · Chemotherapy-induced ovarian failure · Neoadjuvant endocrine therapy

\begin{abstract}
Background: Endocrine therapy with a standard duration of 5 years is well known as an effective treatment for endocrinesensitive breast cancer. Summary: In the adjuvant setting this treatment reduces the 15-year mortality rates by about 30 and $40 \%$ with tamoxifen and aromatase inhibitor, respectively. The well-known long-term recurrence risk of luminal cancers led to multiple trials examining the benefit of extended endocrine treatment for up to 15 years. Additional benefit with extended therapy was seen for patients with high recurrence risk. Also, additional ovarian suppression for premenopausal women exhibited a significant benefit for patients at higher risk. Key Messages: The data of the last years will be summarized and discussed, also considering the side effects of the different treatment options.
\end{abstract}

(c) 2020 S. Karger AG, Base

\section{Introduction}

The risk of dying from breast cancer in the USA and Europe has declined by more than one third in the past 4 decades, owing to a combination of early detection and improved therapy [1]. Estrogen is known as a key regulator of breast tissue growth and differentiation. About 75\% off all breast cancers are estrogen receptor (ER) positive. The cellular effect works through binding and activating the nuclear ER. Activated, the receptors exhibit transcriptional and membrane localized signaling activities. The majority of breast cancers express ER $\alpha$ (70\%), while ER $\beta$ is less well characterized. The potential role of estrogen in breast tissue was first noted by George T. Beatson. In 1895 he performed an oophorectomy on a premenopausal patient with unresectable breast cancer. She had complete remission and survived another 4 years. Research over the next decades lead to the discovery of tamoxifen in 1967 by Harper and Walpole [2]. Tamoxifen is a nonsteroidal antiestrogen recommended for adjuvant treatment of patients with ER-positive tumors since 1985. In 2005 the Early Breast Cancer Trialists' Cooperative Group (EBCTCG) [3] described that 5 years of adjuvant tamoxifen in patients with ER-positive breast cancer resulted in a reduction in the breast cancer mortality rate by $31 \%$ and was more effective than 1 or 2 years of tamoxifen therapy. In 2011 the follow-up meta-analysis showed that 5 years of adjuvant tamoxifen in patients with ER-positive breast cancer significantly reduced disease recurrence throughout the first 10 years and reduced breast cancer mortality by approximately one-third throughout the first 15 years [4]. Till today tamoxifen is important in the treatment of endocrine-sensitive breast cancer. In postmenopausal women, estrogen is no longer produced by ovarian tissue and is predominantly synthesized from nonglandular sources via aromatase. This enzyme can be found in a number of tissues including subcutaneous fat, liver, and muscle and has also been isolated from breast cancer cells [5-7]. The aromatase inhibitors (AIs) used today are third-generation AIs that have increased specificity for aromatase and are either steroidal (irreversible inhibition of enzymatic activity, type I) or nonsteroidal (reversible competitive inhibitors, type II). The approval studies for 
treatment of postmenopausal women with comparison of AIs versus tamoxifen were the ATAC-Trial (anastrozole) and the BIG 1-98-Trial (letrozole). In the ATAC Trial $(9,366$ patients) after a median follow-up of 68 months, anastrozole significantly improved disease-free survival (DFS) (575 vs. 651 events), time to recurrence (402 vs. 498 ), distant recurrences (324 vs. 375 ), and contralateral breast cancers ( 35 vs. 59$)[8,9]$.

In the BIG 1-98 Trial (letrozole, 8,010 patients) the letrozole group had an improved 5-year DFS rate compared to the tamoxifen group ( 84.0 and $81.4 \%$, respectively) [10-13]. In 2015 a third meta-analysis of the EBCTCG described the additional benefit of AIs in comparison to tamoxifen. For postmenopausal patients the choice remains between different treatment regimens: AI monotherapy for 5 years, sequenced treatment with tamoxifen and AIs for 5 years, extended tamoxifen monotherapy for 10 years, or tamoxifen followed by extended AIs for 10 years. Their meta-analysis showed that 5-year adjuvant endocrine treatment including AIs was more effective than tamoxifen monotherapy in preventing recurrence and breast cancer death in either continuous or sequential regimens [14]. There are no data to support the preference of one of the available AIs for NST carcinomas. There might be a small benefit of anastrozole compared to exemestane for lobular carcinomas [15].

To further improve the outcome for patients with ERpos/HER2-neg breast cancer the additional benefit of adjuvant chemotherapy, extended endocrine therapy (ET), ovarian suppression for premenopausal women, bisphosphonate treatment for postmenopausal women, as well as life-style factors and new substances such as CDK4/6 inhibitors should be considered. To evaluate the absolute treatment benefit the risk of recurrence needs to be assessed. Today this is estimated by a combination of tumor extension, tumor biology, age, and patient conditions. Gene expression profiling is one helpful additional factor for defining risk [16]. There are different tests to define the prognosis in luminal breast carcinomas and to support the decision making in respect of additional chemotherapy [17]. Those tests might also be helpful to estimate the risk of late recurrence.

\section{The Risk of Late Recurrence}

Hormone receptor-positive breast cancers are characterized by a risk of late recurrence for years. Recurrences occur at a steady rate throughout the period from 5 to 20 years, strongly correlated with the original tumor and nodal status and the tumor grade. At least $50 \%$ of recurrences occur more than 5 years after diagnosis. The longterm risk of recurrence is about $1-2 \%$ per year. Estimating the risk of recurrence accurately is important because if the risk is low, even the most effective adjuvant therapy can only result in limited overall improvement. In an analysis by Pan et al. [18], after 5 years of ET for patients with stage $\mathrm{T} 1$ disease the risk of distant recurrence in the period from 5 to 20 years was $13 \%$ for N0, 20\% with N1-3 status, and 34\% with N4-9 status. Among T2 tumors, the risks were 19,26 , and $41 \%$, respectively. Considering the impact of grade among patients with T1 N0 disease, the risk of distant recurrence was $10 \%$ for low-grade and $17 \%$ for high-grade disease. An EBCTCG analysis on this question presented by Pan et al. [19] showed an improved outcome for patients after only 5 years of ET diagnosed after the year 2000 in comparison with diagnosis of breast cancer before the year 2000. Possible explanations for the $25 \%$ reduction of distant recurrences in years 5-9 are the detection of lower-risk lesions by early detection and screening, an improved compliance to treatment and treatment guidelines, and real treatment improvements.

\section{Extended Endocrine Treatment}

Results of several randomized trials suggest that extending adjuvant endocrine treatment beyond 5 years can improve DFS. The ATLAS (Adjuvant Tamoxifen - Longer Against Shorter) trial $(n=6,846)$ demonstrated that extending tamoxifen to 10 years significantly reduced breast cancer recurrence (617 vs. 711 events), breast cancer mortality (331 vs. 397 deaths), and overall mortality (639 vs. 722 deaths) [20]. However, the absolute benefit was small and extended treatment was not without adverse effects. A total of 3,428 patients were treated for 10 years with tamoxifen to avoid 66 breast cancer deaths (so the number needed to treat was 52 to avoid one death), while 53 extra endometrial cancers and 20 extra pulmonary emboli were observed in the treatment group. Confirming these data, the aTTOM trial showed continuing tamoxifen to year 10 produced a reduction in recurrence $(580 / 3,468$ vs. $678 / 3,485 ; p=0.003)$ from year 7 onward [21].

Trials investigating the use of AIs after 5 years of tamoxifen treatment - ABCSG-6a (anastrozol), MA.17 (letrozol), NSABP B33 (exemestane) - all showed a benefit of 5 years of AI treatment after an initial 5 years of tamoxifen in DFS [22-24]. For example, the early interim analysis MA. 17 trial $(n=1,918)$ after a median of 2.5 years of follow-up showed that treatment with letrozole after 5 years of tamoxifen therapy improved DFS (95 vs. 91\%; $p=0.01$; HR 0.58). There was also an improvement in overall survival (OS), but this was not statistically significant because after unblinding $60 \%$ of placebo patients crossed over to letrozole [25] Goss et al. [26] presented an evaluation of the MA.17 study which showed that perimenopausal patients who entered the study after 5 years 
Table 1. Endocrine treatment of early breast cancer

\begin{tabular}{|c|c|c|c|c|}
\hline $\begin{array}{l}\text { Menopausal status at } \\
\text { time of diagnosis }\end{array}$ & $\begin{array}{l}\text { Type of } \\
\text { endocrine therapy }\end{array}$ & Reasons for therapy selection & $\begin{array}{l}\text { Extended therapy: } \\
\text { considerations }\end{array}$ & Type of extended therapy \\
\hline \multirow[t]{4}{*}{ Postmenopausal } & AI (5 years) & $\begin{array}{l}\text { High risk of early relapse } \\
\text { History of thromboembolic disease } \\
\text { Depression }\end{array}$ & $\begin{array}{l}\text { No significant OS benefit } \\
\text { Shared decision making if } \\
\text { N2, N3, and AI well tolerated }\end{array}$ & AI (2 years) \\
\hline & $\begin{array}{l}\text { AI }(2-3 \text { years })-> \\
\text { Tam }(2-3 \text { years })\end{array}$ & $\begin{array}{l}\text { Higher risk } \\
\text { Relevant cardiovascular disease }\end{array}$ & $\begin{array}{l}\text { High risk, e.g., N2, N3, and } \\
\text { treatment well tolerated }\end{array}$ & $\begin{array}{l}\text { AI ( } 2-5 \text { years }) \text { or } \\
\text { Tam }(2-5 \text { years })\end{array}$ \\
\hline & $\begin{array}{l}\text { Tam }(2-3 \text { years })-> \\
\text { AI }(2-3 \text { years })\end{array}$ & $\begin{array}{l}\text { Intermediate risk } \\
\text { Osteopenia/osteoporosis } \\
\text { Relevant cardiovascular disease }\end{array}$ & $\begin{array}{l}\text { High risk, e.g., N2, N3, and } \\
\text { treatment well tolerated }\end{array}$ & $\begin{array}{l}\text { AI ( } 2-5 \text { years }) \text { or } \\
\text { Tam }(2-5 \text { years })\end{array}$ \\
\hline & Tam (5 years) & Low risk & Higher risk & $\begin{array}{l}\text { AI ( } 2-5 \text { years }) \text { or } \\
\text { Tam }(5 \text { years })\end{array}$ \\
\hline \multirow[t]{4}{*}{$\begin{array}{l}\text { Peri- and } \\
\text { Premenopausal }\end{array}$} & Tam (5 years) & Low and intermediate risk & Intermediate risk & $\begin{array}{l}\text { Tam }(5 \text { years }) \text { or } \\
\text { AI ( } 2-5 \text { years }) \text { if } \\
\text { postmenopausal }^{\text {a }}\end{array}$ \\
\hline & $\begin{array}{l}\text { Tam }(5 \text { years })+ \\
\text { OFS }(2-5 \text { years })\end{array}$ & $\begin{array}{l}<35 \text { years or } \\
\text { becoming premenopausal during the } \\
2 \text { years following chemotherapy }\end{array}$ & High risk & $\begin{array}{l}\text { Tam }(5 \text { years }) \text { or } \\
\text { AI ( } 5 \text { years }) \text { if } \\
\text { postmenopausal }^{\text {a }}\end{array}$ \\
\hline & OFS (up to 5 years) & $\begin{array}{l}\text { Tam contraindicated and } \\
\text { low risk }\end{array}$ & - & - \\
\hline & $\mathrm{AI}+\mathrm{OFS}$ (5 years) & $\begin{array}{l}\text { Tam contraindicated and } \\
\text { intermediate or high risk }\end{array}$ & - & - \\
\hline
\end{tabular}

AI, aromatase inhibitor; Tam, tamoxifen; OFS, ovarian function suppression; COF, chemotherapy-induced ovarian failure. ${ }^{\text {a }}$ Testing of E2/FSH after COF repeatedly before and during treatment. Treat osteopenia and osteoporosis according to guidelines; consider bisphosphonate oral or intravenous in osteoprotective dosage for patients (1) more than 5 years after menopause or (2) during therapy with AI or OFS.

of tamoxifen had the largest DFS benefit (HR 0.26; $p=$ $0.0003)$.

The NSABP (National Surgical Adjuvant Breast and Bowel Project) B-42 trial $(n=3,923)$ compared 5 years of ET including an AI versus 5 additional years of letrozole and showed a $3 \%$ nonsignificant improvement in DFS (84 vs. $81 \%$; HR 0.85 ) and a significant $28 \%$ reduction in distant recurrence (3.9 vs. 5.8\%; HR 0.72) [27]. Thus, approximately 2,000 patients were treated to observe a $2 \%$ decrease in metastatic recurrence, while the risk of osteoporosis increased. The DATA trial $(n=1,912)$ compared 3 versus 6 years of anastrozole therapy after 2-3 years of tamoxifen therapy. Only in subgroup analysis of women with high-risk tumors was extended ET associated with an improved DFS. For instance, in women with nodepositive disease, 5 -year DFS was $84 \%$ in the 6-year group versus $76 \%$ in the 3 -year group (HR 0.64 ); and 83 versus $69 \%$ if they also had a larger tumor size ( $\geq$ T2; HR 0.53$)$ [28]. The IDEAL trial investigated the use of 2.5 versus 5 years of letrozole after an initial 5 years of endocrine treatment. The initial treatment could either be tamoxifen monotherapy, AI monotherapy, or a sequential regimen. Regardless of the initial treatment regimen, no statistically significant benefit in DFS and OS was found for 5 years of extended letrozole treatment in comparison to an extended 2.5 years of AI treatment [29]. The AERAS trial $(n=1,697)$ compared 5 versus 10 years of anastrozole therapy and demonstrated improved DFS ( 91.9 vs. $84.4 \%$; HR $0.548 ; p<0.001)$ and distant metastasis-free survival (97.2 vs. $94.3 \%$; HR, 0.514; $p=0.0077$ ) with extended therapy in Asian women [30]. A different approach was tested in the SOLE trial. Here the hypothesis was tested that endocrine resistance to AI could be reversed by withdrawal and reintroduction. Postmenopausal women previously treated with 5 years of endocrine treatment were randomized to 5 years of intermittent letrozole or continuous letrozole. Intermittent letrozole use did not improve DFS compared with continuous letrozole use (HR 1.08). Adverse events were reported as expected and were similar between the 2 groups, including arthralgias [31]. An EBCTCG meta-analysis presented at SABCS 2018 by Gray showed a 33\% risk reduction for any recurrence with extended AI therapy after approximately 5 years of tamoxifen, corresponding to a 5-year gain of 3.6\% $(p<$ $0.00001)$; a $23 \%$ reduction in the risk of distant recurrence, with a 5 -year gain of $1.5 \%(p=0.008)$; and a $23 \%$ reduction in breast cancer mortality, with a 5 -year gain of $0.8 \%(p=0.05)$, respectively [32]. However, no reduction 
in breast cancer mortality could be found for extended AI therapy after 5 years of an AI alone or after extended therapy with tamoxifen. Recent meta-analyses including these trials showed that extended adjuvant ET with AIs beyond 5 years in postmenopausal women with early breast cancer reduced the occurrence of secondary breast tumors, but had no or only a small impact on distant metastasis-free survival as well as OS [33-36]; and the benefit of extended therapy with an AI was restricted to patients at high risk (node positive and/or large tumors) or after initial treatment with 5 years of tamoxifen alone. The ASCO guidelines recommend an extended adjuvant therapy only for high-risk patients with ER-positive disease [37]. The AGO 2020 recommends assessing the baseline risk profile of the disease as well as the wish of the patient after 5 years of experience with endocrine treatment and its side effects [38]. Extended treatment should be considered for patients with higher risks and good tolerance of the treatment so far (Table 1).

\section{Prognostic Tools to Assess the Risk of Late Recurrence}

The Clinical Treatment Score post 5 Years (CTS5) is a late-recurrence predictor that includes tumor size, the number of positive nodes, histologic grade, and age. The score was developed from the ATAC data and validated with the BIG 1-98 data set. The model is freely available at www.cts5-calculator.com [39]. The score is probably less reliable for premenopausal patients [40].

The molecular features of the individual breast cancer are used by the commercially available gene signatures which derive their prognostic power from quantifying proliferation and ER-related genes. Proliferation- and ER-associated gene expression also shows a time-dependent interaction with risk of recurrence. In tamoxifentreated patients, low proliferation and low-ER signaling, quantified through mRNA expression, define a group of patients with continuously increasing risk of relapse over time, whereas cancers with high- proliferation and highER signaling show a low risk of early relapse but a high risk of late relapse [41].

In 2018, Sestak et al. [17] presented the comparison the of 6 multigene signatures: Oncotype $\mathrm{Dx}^{\circledR} \mathrm{RS}$, the Breast Cancer Index (BCI), the PAM50 Prosigna Risk of Recurrence (ROR) score, EndoPredict (EPclin), Clinical Treatment Score, and 4-marker immunohistochemical score in women with early ER-positive breast cancer who were treated with ET for 5 years within the ATAC trial. Only ROR, BCI, and EPclin provided prognostic information for late recurrences between years 5 and 10 . Patients with node-negative disease who were classified as low risk for late recurrence by the $\mathrm{BCI}$, the ROR, and EpClin experi- enced a 3,1 , and $4 \%$ recurrence rate, respectively. Individuals classified as high risk experienced a 15, 23, and $15 \%$ recurrence rate, respectively, if they were node negative, and 36,25 , and $24 \%$ risk if they had $1-3$ positive nodes.

However, having substantial risk for late recurrence does not automatically imply sensitivity to endocrine treatment and therefore a benefit from extended therapy. Currently, only the BCI assay reports predicted benefit to extended ET independent of risk of late recurrence. The BCI combines a 5-gene Molecular Grade Index that captures cell proliferation-related $\mathrm{mRNA}$ expression, and the HOXB13 to IL17BR mRNA expression ratio (H:I) that informs about the likelihood of benefit from ET [42]. The prognostic value of the BCI was evaluated in several retrospective clinical studies including patients with none to 3 positive nodes [43-46]. The predictive value of the BCI was assessed on tissues from the MA.17 and the aTTom trial. High H:I ratio identified a subgroup of patients who benefitted significantly from extended therapy. The absolute risk reduction from extended ET for patients with high $\mathrm{H}: \mathrm{I}$ was $16.5 \%$ (letrozole, MA.17 trial) and 10.2\% (tamoxifen, aTTom trial) $[47,48]$.

The comparison of clinical and molecular risk estimation (CTS5- and BCI-predicted risk) in 119 patients with stage I or II, ER-positive breast cancer ( $85 \%$ of low-tointermediate histologic grade; $78 \%$ node negative) showed classification with the BCI assay in $54 \%$ of patients as low risk $(0-5 \%$ risk of recurrence in years $5-10)$ and $46 \%$ as high risk ( $>5 \%$ risk). The CTS5 predictor, using the same thresholds, categorized 61 and 39\% of patients as low and high risk, respectively $[49,50]$.

Because clinical and molecular variables provide independent prognostic value, the most accurate prognostic predictions require combined clinical and molecular variable-based models; and molecular models might provide additional predictive value.

\section{The CYP2D6 Discussion}

Tamoxifen is considered a prodrug, because it binds to ER with a much lower affinity than 2 of its metabolites, 4-hydroxy tamoxifen and endoxifen [51]. The metabolism depends on the activity of CYP2D6, a hepatic enzyme. The variable metabolism of drugs based on CYP2D6 genotypes separates patients into metabolic phenotypes: poor, intermediate, extensive, and ultra-rapid. Although endoxifen levels are much reduced in patients who are poor CYP2D6 metabolizers, this metabolite is still present, albeit at low concentrations [52]. It is very likely that tumor levels of ER are saturated regardless of whether the parent drug is rapidly or poorly converted to endoxifen. Recently, a report from Swedish breast cancer 
cohort registries linked to the Swedish Prescribed Drug Registry evaluated more than 1,300 patients assigned to take adjuvant tamoxifen. They found that discontinuation rates, presumably because of toxicity, were 7.2, 7.6, 6.7 , and $18.8 \%$ among poor, intermediate, normal, and ultra-rapid CYP2D6 metabolizers, respectively, confirming previously published reports [53-55]. In addition, they observed a breast cancer-specific mortality, with highest rates in the poor and ultra-rapid metabolizer groups, which is rather difficult to explain. There are further studies without an association between endoxifen concentrations or CYP2D6 genotype and relapse-free survival in 667 pre- and postmenopausal patients taking adjuvant tamoxifen [56-58]. However, this is an ongoing controversy [59]. The large multicenter Tamendox trial is focusing on this issue by supplementing endoxifen to a regular tamoxifen therapy based on genotypical or phenotypical features. According to guidelines today the CYP2D6 genotype should not be used to guide ET for women with ER-positive early or metastatic breast cancer [38, $60,61]$.

\section{Ovarian Function Suppression for Premenopausal Patients}

To optimize the endocrine treatment for premenopausal patients, ovarian function suppression (OFS) was tested in the SOFT and TEXT trials [62-65]. Premenopausal women were randomly assigned to receive 5 years of tamoxifen, tamoxifen plus OFS, or exemestane plus OFS in SOFT and to receive tamoxifen plus OFS or exemestane plus OFS in TEXT after chemotherapy. In SOFT, the 8-year DFS rate was $78.9 \%$ with tamoxifen alone, $83.2 \%$ with tamoxifen plus OFS, and $85.9 \%$ with exemestane plus OFS ( $p=0.009$ for tamoxifen alone vs. tamoxifen plus OFS). The 8-year rate of OS was $91.5 \%$ with tamoxifen alone, $93.3 \%$ with tamoxifen plus OFS, and $92.1 \%$ with exemestane plus OFS ( $p=0.01$ for tamoxifen alone vs. tamoxifen plus OFS).

Based on these findings the ASCO panel recommended that "higher-risk patients should receive ovarian function suppression in addition to adjuvant ET, whereas lower-risk patients should not" and that "ovarian function suppression may be administered with either tamoxifen or an aromatase inhibitor." Furthermore, the panel pointed out that "clinicians should be alert to the possibility of incomplete ovarian function suppression with gonadotropin-releasing hormone agonist therapy". The recommendations of the AGO-Mamma were more careful, also due to the results of the Austrian Breast Cancer Study Group-12 randomized trial (ABCSG-12) [66]. In this trial, premenopausal women with ER-positive, earlystage breast cancer were randomly assigned to anastro- zole plus OFS or tamoxifen plus OFS with or without zoledronic acid for 3 years. After a median follow-up of 94.4 months, there was no difference in DFS between the anastrozole plus goserelin and tamoxifen plus goserelin groups (absolute DFS rate for anastrozole was 85.1 vs. $87.0 \%$ for tamoxifen (HR 1.13; $p=0.335$ ). However, OS was worse with anastrozole plus goserelin compared with tamoxifen plus goserelin (absolute OS rate for anastrozole was $94.1 \%$ vs. $96.3 \%$ for tamoxifen; HR $1.63 ; p=0.03$ ) [66]. The discordant results for distant recurrence and OS are surprising, and the factors underlying this discordance are not clear but persistent [67]. The adequacy of estrogen suppression with gonadotropin-releasing hormone agonists in premenopausal women with early breast cancer has been questioned. If the combination is chosen, a frequent monitoring of adequate suppression of FSH and estradiol (E2) is mandatory. Due to different laboratory tests there is no absolute threshold for the E2 level. Taken together, these findings suggest that tamoxifen plus OFS represents a prudent approach for the management of premenopausal women with early-stage, ERpositive breast cancer at risk $[67,68]$. A recent publication of an Asian trial $(n=1,282)$ confirms a DFS benefit of tamoxifen in combination with OFS for women aged $<45$ years who are premenopausal within 2 years after chemotherapy [69]. The estimated 5-year DFS rate was $91.1 \%$ in the tamoxifen + OFS group and $87.5 \%$ in the tamoxifenonly group (HR $0.69 ; 95 \%$ CI $0.48-0.97 ; p=0.033$ ). The estimated 5-year OS rate was $99.4 \%$ in the tamoxifen + OFS group and $97.8 \%$ in the tamoxifen-only group (HR, $0.31 ; 95 \%$ CI $0.10-0.94 ; p=0.029$ ).

OFS can be initiated concurrently with or after chemotherapy [65]. Starting before chemotherapy supports fertility preservation $[70,71]$.

Even if there are no data the AGO-Mamma recommends an extended treatment with another 5 years of tamoxifen after 5 years of tamoxifen plus OFS for premenopausal women at risk (Table 1).

\section{Al in Women with Chemotherapy-Induced Ovarian Failure}

Chemotherapy-induced ovarian failure (COF) must not guide a treatment decision in the direction of an $\mathrm{AI}$ even after 2-3 years of tamoxifen. van Hellemond et al. [72] reported an analysis of endocrine data of 329 DATA study participants with COF. In the DATA study all patients had taken tamoxifen prior to anastrozole for 2-3 years. These patients had a median age of 50 years (range 45-57 years). Thirty-nine patients (12.4\%) developed ovarian function recovery (OFR) under treatment with AI. Of these, 11 (28.2\%) were aged 50 years or older at AI initiation. The estradiol level decreased statistically sig- 
nificantly for all women under AI treatment. However, the estradiol levels in the women who experienced OFR remained higher prior to OFR diagnosis compared with those who did not experience OFR. The 30-month OFR was $5.1 \%$ for patients aged 50 years or older vs. $25.2 \%$ for patients younger than 50 years. The results are in line with earlier smaller studies which described OFR rates of about $30 \%$ under treatment with $\mathrm{AI}$ in women with COF.

\section{Side Effects of Endocrine Treatment}

The main side effects of tamoxifen and AIs are partially different [73]. Menopausal symptoms such as sleeping disorders, vaginal dryness, and loss of sexual interest are characteristic for both treatments. The risk of venous thromboembolic events, endometrial cancer, depression, and hot flashes are dominant in patients treated with tamoxifen. With AI a decrease in bone mineral density, a higher risk of osteoporotic fractures, and musculoskeletal symptoms (arthralgia and myalgia) were observed more often. Assessments of side effects were also consistent with a higher risk of vascular diseases such as myocardial infarction and angina in AI users compared with tamoxifen users, but there was also a suggestion that this may be partly driven by a protective effect of tamoxifen on these outcomes [74]. In the SOFT trial thrombosis or embolism were reported in $2 \%$ of the patients with tamoxifen, and grade 3-4 musculoskeletal symptoms in about $6 \%$ of patients with tamoxifen and in $11.4 \%$ of the AI group. Osteoporosis (T-score $<-2.5$ ) was seen in 3.9, 7.2, and 14.8\% of patients with treatment of tamoxifen, tamoxifen combined with ovarian suppression, and exemestane combined with OFS, respectively $[75,76]$.

In a meta-analysis of 21 studies (13,177 participants) prevalence rates of musculoskeletal symptoms ranged from 20 to $70 \%$. Another meta-analysis including 7 trials comprising 16,349 patients analyzed the reported toxicity of extended endocrine treatment with AIs [77]. Longer treatment with AIs was associated with increased odds of cardiovascular events (OR 1.18; $p=0.05$, number needed to harm $=122)$, bone fractures (OR 1.34, $p=0.001$, number needed to harm $=72$ ). Extended use of AIs did not influence the odds of a second malignancy (OR 0.93), but a numerical excess of deaths without breast cancer recurrence was found with prolonged AI (OR $1.11 ; p=0.34)$.

Compliance is an important issue in adjuvant ET in general because it influences the efficacy. An analysis of the BIG 1-98 trial looked at treatment adherence and its impact on DFS in patients on tamoxifen, letrozole, or a sequential regimen for 5 years [78]. Both early cessation and a low compliance score were associated with a reduced DFS. Sequential treatments were associated with higher rates of nonpersistence (tamoxifen-letrozole, $20.8 \%$; letro- zole-tamoxifen, $20.3 \%$; tamoxifen $16.9 \%$; letrozole 17.6\%). In $82.7 \%$ of patients, adverse events were the reason for discontinuation. Other studies showed that younger age is a predictor of premature discontinuation of tamoxifen [79]. For both tamoxifen and AIs, the probability of early termination increases with a longer treatment duration: about $15 \%$ discontinuation during the first year of treatment, which increased to up to $45 \%$ at 5 years [80].

\section{Definition of Endocrine-Sensitive Tumors}

ER positivity and therefore endocrine responsiveness is assumed for tumors with $>1 \%$ ER-positive tumor cells. However, the ER low-positive group is characterized molecularly by having features of triple-negative breast cancer in the majority of cases as basal-like phenotype, high incidence of germline BRCA mutation, and high-risk score by Oncotype $\mathrm{DX}^{\circledR}$. Also, distant DFS is similar to triple-negative breast cancer in these cases. Therefore, a low threshold of $1 \%$ for ER positivity may include clinically insignificant ER expression and may lead to the false categorization of biologically ER-negative tumors as positive ones $[81,82]$. In these patients, adjuvant chemotherapy is usually indicated. The exclusive use of IHC scores is discouraged [82].

\section{CDK4/6 Inhibition in Early-Stage ER-Positive Breast Cancer}

The exciting results observed with CDK4/6 inhibitors in the treatment of advanced ER-positive, HER2-negative breast cancer [83] have triggered the evaluation of these agents in the early-stage setting. For example, results of a neoadjuvant therapy setting were presented by Dowsett et al. [84] from the PALLET study. In this study, palbociclib was given in addition to 3 months of the AI letrozole. It was shown that the antiproliferative effect of the $\mathrm{AI}$ is substantially increased by palbociclib. The percentage of tumors which underwent a complete cell cycle arrest in the form of a Ki- 67 value $<2.7 \%$ during neoadjuvant therapy was able to be increased through the addition of palbociclib from 58.5 to $90.4 \%$. In the (post-neo) adjuvant setting the PALLAS study has included 4,600 patients with stage II and III breast cancer and randomized between standard endocrine treatment $+/$ - palbociclib. Comparable study concepts exist for abemaciclib (monarchE study) and ribociclib (EarLEE-1, NataLEE).

The ADAPTcycle study follows a different approach: the comparison of ET plus ribociclib versus standard chemotherapy in intermediate-risk ER+/HER2- early breast cancer.

Results are eagerly awaited to establish new treatment options for early luminal B breast cancers. 


\section{Neoadjuvant Endocrine Therapy}

Neoadjuvant endocrine therapy (NET) has a well-established role in senior patients with ER-sensitive breast cancer for whom surgery is not indicated or should be delayed [85]. In the neoadjuvant setting of postmenopausal disease AIs are more effective than tamoxifen with response rates of about $60 \%$ and an improved breast conservation rate [86, 87]. For postmenopausal patients with low-risk ER-positive early breast cancer who want to avoid a neoadjuvant chemotherapy as well as a mastectomy, NET with an AI for up to 6 months is a reasonable option $[88,89]$.

Lately, the NET setting has developed as a platform for scientific issues as the validation of biomarkers of prognostic and predictive information, drug resistance, and the evaluation of targeted therapy combinations. Pathological complete response, an approved surrogate marker for longterm outcome of neoadjuvant chemotherapy, is not feasible for evaluating NET. However, for example, therapy-induced changes in the proliferation marker Ki-67 and the Preoperative Endocrine Prognostic Index (PEPI), a score of posttreatment ER, Ki-67, tumor size, and nodal status are used as markers for evaluation of response in NET trials [90, 91]. After ET with an AI for 2-4 weeks, about $70 \%$ of patients showed levels of Ki-67 positive cells $\leq 10 \%$ (nuclear staining) and this correlated with excellent long-term outcome [92]. And recently, in the POETIC trial patients with low baseline Ki-67 $(<10 \%)$ had an excellent 5-year DFS compared to that in patients with high Ki-67 (Ki-67 $\geq 20 \%)$ and no drop of Ki-67 after ET (5-year DFS 95.5 and 80.4\%, respectively). Patients with luminal-B-like tumors and good response to ET (Ki-67 $<10 \%$ after short ET) had a better outcome than those with poor ET response, yet it was still somewhat worse than that in "baseline luminal-A-like" tumors (5-year DFS of 91.1\%) [93]. In the ADAPT trial, about $70-80 \%$ of patients with genomically low-to-intermediate risk and about $40 \%$ of those with genomically highrisk disease responded to preoperative ET by decrease of the proliferation marker Ki-67 $\leq 10 \%$ [94].

The effect of decreased proliferation after neoadjuvant treatment can be increased by adding a CDK4/ 6 inhibitor to ET. In the neoMONARCH study, more patients in the abemaciclib-containing arms versus anastrozole alone achieved complete cell cycle arrest (Ki-67 $\leq 2.7 \%)$ after 2 weeks of ET ( $68 / 58$ vs. $14 \%$; $p<0.001)$. At the end of treatment, following 2 weeks lead-in and 14 weeks of combination therapy, $46 \%$ of intent-to-treat patients achieved a radiologic response, with pathologic complete response observed in 4\% [95]. As another example, the results of the CORALLEEN trial were presented at SABCS 2019; 106 postmenopausal patients with early luminal B breast cancer (PAM 50) were randomized between standard multiagent chemotherapy and ribociclib plus letrozole. The endpoint was the achievement of ROR-low disease after 6 months of treatment evaluated at the time of surgery. In both treatment arms almost $50 \%$ of the patients reached this endpoint [96]. These trial settings will help to gain knowledge about breast cancer in short-time intervals and will help us to optimize personalized treatment.

\section{Conclusions}

- The standard endocrine treatment for pre- and perimenopausal patients is 5 years of tamoxifen, and for postmenopausal patients 5 years of an $\mathrm{AI}$ or a sequence of $\mathrm{AI}$ and tamoxifen.

- Extended ET with an AI should be discussed with postmenopausal patients at risk, considering the side effects.

- Risk can be assessed by clinical features as tumor size, nodal status, grading, and age (CTS5 score) as well as by gene expression profiling.

- The need for osteoprotective therapy should be assessed early on.

- Ten years of tamoxifen should be recommended for premenopausal patients at risk.

- Additional OFS for 2-5 years should be discussed with patients younger than 35 years or if menstruation starts again within 2 years after chemotherapy.

- There are discordant results for distant recurrence (better) and OS (worse) with the combination of exemestane with OFS in premenopausal women.

- Control of adequate OFS when giving AI to premenopausal women is mandatory.

- CYP2D6 genotypes should not be used to guide the selection of ET.

- Careful consideration of treatment recommendation in the low ER-positive situation is needed.

- Trial results with integration of CDK4/6 inhibitors in the treatment of early luminal B carcinomas are awaited.

NET and preoperative short-term ET are promising tools for the treatment and understanding of luminal carcinomas.

\section{Conflict of Interest Statement}

The authors have no conflict of interest to declare for this specific work.

\section{Funding Sources}

There are no funding sources to declare.

\section{Author Contributions}

K.K. and E.S. both contributed to the review of the literature and writing. 


\section{References}

1 DeSantis CE, Ma J, Gaudet MM, Newman LA, Miller KD, Goding Sauer A, et al. Breast cancer statistics, 2019. CA Cancer J Clin. 2019 Nov;69(6):438-51.

2 Tremont A, Lu J, Cole JT. Endocrine Therapy for Early Breast Cancer: updated Review. Ochsner J. 2017;17(4):405-11.

3 Early Breast Cancer Trialists' Collaborative Group. A Comparison of Letrozole and Tamoxifen in Postmenopausal Women with Early Breast Cancer. N Engl J Med. 2005; 353(26):2747-57.

4 Early Breast Cancer Trialists' Collaborative Group (EBCTCG); Davies C, Godwin J, Gray R, Clarke M, Cutter D, Darby S, et al. Relevance of breast cancer hormone receptors and other factors to the efficacy of adjuvant tamoxifen: patient-level meta-analysis of randomised trials. Lancet. 2011 Aug;378(9793): 771-84.

5 Brodie A, Long B, Lu Q. Aromatase expression in the human breast. Breast Cancer Res Treat. 1998;49(Suppl 1):S85-91.

6 Brodie A, Sabnis G, Jelovac D. Aromatase and breast cancer. J Steroid Biochem Mol Biol. 2006 Dec;102(1-5):97-102.

7 Richards JA, Petrel TA, Brueggemeier RW. Signaling pathways regulating aromatase and cyclooxygenases in normal and malignant breast cells. J Steroid Biochem Mol Biol. 2002 Feb;80(2):203-12.

8 Howell A, Cuzick J, Baum M, Buzdar A, Dowsett M, Forbes JF, et al.; ATAC Trialists' Group. Results of the ATAC (Arimidex, Tamoxifen, Alone or in Combination) trial after completion of 5 years' adjuvant treatment for breast cancer. Lancet. 2005 Jan; 365(9453):60-2.

9 Cuzick J, Sestak I, Baum M, Buzdar A, Howell A, Dowsett M, et al.; ATAC/LATTE investigators. Effect of anastrozole and tamoxifen as adjuvant treatment for early-stage breast cancer: 10-year analysis of the ATAC trial. Lancet Oncol. 2010 Dec;11(12):1135-41.

10 Breast International Group (BIG) 1-98 Collaborative Group; Thürlimann B, Keshaviah A, Coates AS, Mouridsen H, Mauriac L, Forbes JF, et al. A comparison of letrozole and tamoxifen in postmenopausal women with early breast cancer. N Engl J Med. 2005 Dec; 353(26):2747-57.

11 Coates AS, Keshaviah A, Thürlimann B, Mouridsen H, Mauriac L, Forbes JF, et al. Five years of letrozole compared with tamoxifen as initial adjuvant therapy for postmenopausal women with endocrine-responsive early breast cancer: update of study BIG 1-98. J Clin Oncol. 2007 Feb;25(5):486-92.

12 Regan MM, Neven P, Giobbie-Hurder A, Goldhirsch A, Ejlertsen B, Mauriac L, et al. BIG 1-98 Collaborative Group; International Breast Cancer Study Group (IBCSG). Assessment of letrozole and tamoxifen alone and in sequence for postmenopausal women with steroid hormone receptor-positive breast cancer: the BIG 1-98 randomised clinical trial at 8.1 years median follow-up. Lancet Oncol. 2011 Nov;12(12):1101-8.
13 Ruhstaller T, Giobbie-Hurder A, Colleoni M, Jensen MB, Ejlertsen B, de Azambuja E, et al.; members of the BIG 1-98 Collaborative Group and the International Breast Cancer Study Group. Adjuvant Letrozole and Tamoxifen Alone or Sequentially for Postmenopausal Women With Hormone Receptor-Positive Breast Cancer: Long-Term Follow-Up of the BIG 1-98 Trial. J Clin Oncol. 2019 Jan;37(2):105-14.

14 Early Breast Cancer Trialists' Collaborative Group (EBCTCG). Aromatase inhibitors versus tamoxifen in early breast cancer: patientlevel meta-analysis of the randomised trials. Lancet. 2015 Oct;386(10001):1341-52.

15 Strasser-Weippl K, Sudan G, Ramjeesingh R, Shepherd LE, O'Shaughnessy J, Parulekar $\mathrm{WR}$, et al. Outcomes in women with invasive ductal or invasive lobular early stage breast cancer treated with anastrozole or exemestane in CCTG (NCIC CTG) MA.27. Eur J Cancer. 2018 Feb;90:19-25.

16 Sparano JA, Gray RJ, Ravdin PM, Makower DF, Pritchard KI, Albain KS, et al. Clinical and Genomic Risk to Guide the Use of Adjuvant Therapy for Breast Cancer. N Engl J Med. 2019 Jun;380(25):2395-405

17 Sestak I, Buus R, Cuzick J, Dubsky P, Kronenwett R, Denkert C, et al. Comparison of the Performance of 6 Prognostic Signatures for Estrogen Receptor-Positive Breast Cancer: A Secondary Analysis of a Randomized Clinical Trial. JAMA Oncol. 2018 Apr;4(4):545-53.

18 Pan H, Gray R, Braybrooke J, Davies C, Taylor C, McGale P, et al.; EBCTCG. 20-Year Risks of Breast-Cancer Recurrence after Stopping Endocrine Therapy at 5 Years. N Engl J Med. 2017 Nov;377(19):1836-46.

19 Pan $\mathrm{H}$, et al. EBCTCG, Improvements since 2000 in the outcome of ER+ disease after 5 years of adjuvant endocrine therapy: Analyses of 86,000 women in 110 trials. SABCS 2019, \#GS2.

20 Davies C, Pan H, Godwin J, Gray R, Arriagada R, Raina V, et al.; Adjuvant Tamoxifen: Longer Against Shorter (ATLAS) Collaborative Group. Long-term effects of continuing adjuvant tamoxifen to 10 years versus stopping at 5 years after diagnosis of oestrogen receptorpositive breast cancer: ATLAS, a randomised trial. Lancet. 2013 Mar;381(9869):805-16.

21 Gray RG, Rea D, Handley K, Bowden SJ, Perry P, Earl HM, et al. aTTom: long-term effects of continuing adjuvant tamoxifen to 10 years versus stopping at 5 years in 6,953 women with early breast cancer. J Clin Oncol. 2013; 31(15_suppl suppl 18):5.

22 Jakesz R, Greil R, Gnant M, Schmid M, Kwasny W, Kubista E, et al.; Austrian Breast and Colorectal Cancer Study Group. Extended adjuvant therapy with anastrozole among postmenopausal breast cancer patients: results from the randomized Austrian Breast and Colorectal Cancer Study Group Trial 6a. J Natl Cancer Inst. 2007 Dec;99(24):1845-53.
23 Goss PE, Ingle JN, Martino S, Robert NJ, Muss HB, Piccart MJ, et al. Randomized trial of letrozole following tamoxifen as extended adjuvant therapy in receptor-positive breast cancer: updated findings from NCIC CTG MA.17. J Natl Cancer Inst. 2005 Sep;97(17): 1262-71

24 Mamounas EP, Jeong JH, Wickerham DL, Smith RE, Ganz PA, Land SR, et al. Benefit from exemestane as extended adjuvant therapy after 5 years of adjuvant tamoxifen: intention-to-treat analysis of the National Surgical Adjuvant Breast And Bowel Project B-33 trial. J Clin Oncol. 2008 Apr;26(12):1965-71.

25 Jin H, Tu D, Zhao N, Shepherd LE, Goss PE. Longer-term outcomes of letrozole versus placebo after 5 years of tamoxifen in the NCIC CTG MA.17 trial: analyses adjusting for treatment crossover. J Clin Oncol. 2012 Mar;30(7): 718-21.

26 Goss PE, Ingle JN, Pritchard KI, Ellis MJ, Sledge GW, Budd GT, et al. Exemestane versus anastrozole in postmenopausal women with early breast cancer: NCIC CTG MA.27a randomized controlled phase III trial. J Clin Oncol. 2013 Apr;31(11):1398-404.

27 Mamounas EP, Bandos H, Lembersky BC, Jeong JH, Geyer CE Jr, Rastogi P, et al. Use of letrozole after aromatase inhibitor-based therapy in postmenopausal breast cancer (NRG Oncology/NSABP B-42): a randomised, double-blind, placebo-controlled, phase 3 trial. Lancet Oncol. 2019 Jan;20(1): 88-99.

28 Tjan-Heijnen VC, van Hellemond IE, Peer PG, Swinkels AC, Smorenburg $\mathrm{CH}$, van der Sangen MJ, et al.; Dutch Breast Cancer Research Group (BOOG) for the DATA Investigators. Extended adjuvant aromatase inhibition after sequential endocrine therapy (DATA): a randomised, phase 3 trial. Lancet Oncol. 2017 Nov;18(11):1502-11.

29 Blok EJ, Kroep JR, Meershoek-Klein Kranenbarg E, Duijm-de Carpentier M, Putter H, van den Bosch J, et al.; IDEAL Study Group. Optimal Duration of Extended Adjuvant Endocrine Therapy for Early Breast Cancer; Results of the IDEAL Trial (BOOG 2006-05). J Natl Cancer Inst. 2018 Jan;110(1):40-8.

30 Ohatani SK, Iijima K, Higaki K, et al. A prospective randomized multi-center open-label phase III trial of extending aromatase-inhibitor adjuvant therapy to 10 years - Results from 1697 postmenopausal women in the NSAS BC05 trial: Arimidex extended adjuvant randomized study (AERAS). San Antonio Breast Cancer Symposium 2018; Abstr. GS3042018.

31 Colleoni M, Luo W, Karlsson P, Chirgwin J, Aebi S, Jerusalem G, et al.; SOLE Investigators. Extended adjuvant intermittent letrozole versus continuous letrozole in postmenopausal women with breast cancer (SOLE): a multicentre, open-label, randomised, phase 3 trial. Lancet Oncol. 2018 Jan;19(1):127-38. 
32 Early Breast Cancer Trialists' Collaborative G. Effects of prolonging adjuvant aromatase inhibitor therapy beyond five years on recurrence and cause-specific mortality: An EBCTCG meta-analysis of individual patient data from 12 randomised trials including 24,912 women. San Antonio Breast Cancer Symposium 2018; Abstr. GS3-032018.

33 Rydén L, Heibert Arnlind M, Vitols S, Höistad M, Ahlgren J. Aromatase inhibitors alone or sequentially combined with tamoxifen in postmenopausal early breast cancer compared with tamoxifen or placebo - Meta-analyses on efficacy and adverse events based on randomized clinical trials. Breast. 2016 Apr; 26:106-14.

34 Clement Z, Kollias J, Bingham J, Whitfield R, Bochner M. Extended duration of adjuvant aromatase inhibitor in breast cancer: a metaanalysis of randomized controlled trials. Gland Surg. 2018 Oct;7(5):449-57.

35 Goldvaser H, AlGorashi I, Ribnikar D, Seruga B, Templeton AJ, Ocana A, et al. Efficacy of extended adjuvant therapy with aromatase inhibitors in early breast cancer among common clinicopathologically-defined subgroups: A systematic review and meta-analysis. Cancer Treat Rev. 2017 Nov;60:53-9.

36 Corona SP, Roviello G, Strina C, Milani M, Madaro S, Zanoni D, et al. Efficacy of extended aromatase inhibitors for hormone-receptor-positive breast cancer: A literature-based meta-analysis of randomized trials. Breast. 2019 Aug;46:19-24.

37 Burstein HJ, Lacchetti C, Anderson H, Buchholz TA, Davidson NE, Gelmon KA, et al. Adjuvant Endocrine Therapy for Women With Hormone Receptor-Positive Breast Cancer: ASCO Clinical Practice Guideline Focused Update. J Clin Oncol. 2019 Feb;37(5):423-38.

38 https://www.ago-online.de/leitlinien-empfehlungen/leitlinien-empfehlungen/kommission-mamma - Adjuvante endokrine Therapie in prä- und postmenopausalen Patientinnen.

39 Dowsett M, Sestak I, Regan MM, Dodson A, Viale $G$, Thürlimann $B$, et al. Integration of Clinical Variables for the Prediction of Late Distant Recurrence in Patients With Estrogen Receptor-Positive Breast Cancer Treated With 5 Years of Endocrine Therapy: CTS5. J Clin Oncol. 2018 Jul;36(19):1941-8.

40 Sestak I. et al. Validation of the clinical treatment score post 5 years (CTS5) in women with hormone receptor positive, HER2-negative, node-negative disease from the TAILORx study. SABCS 2019, \#GS4-03. Available from: https://cancerres.aacrjournals.org/content/80/4_Supplement/GS4-03.

41 Bianchini G, Pusztai L, Karn T, Iwamoto T, Rody A, Kelly C, et al. Proliferation and estrogen signaling can distinguish patients at risk for early versus late relapse among estrogen receptor positive breast cancers. Breast Cancer Res. 2013;15(5):R86.

42 Ma XJ, Salunga R, Dahiya S, Wang W, Carney E, Durbecq V, et al. A five-gene molecular grade index and HOXB13:IL17BR are complementary prognostic factors in early stage breast cancer. Clin Cancer Res. 2008 May; 14(9):2601-8
43 Jankowitz RC, Cooper K, Erlander MG, Ma XJ, Kesty NC, Li H, et al. Prognostic utility of the breast cancer index and comparison to Adjuvant! Online in a clinical case series of early breast cancer. Breast Cancer Res. 2011 Oct;13(5):R98.

44 Zhang Y, Schnabel CA, Schroeder BE, Jerevall PL, Jankowitz RC, Fornander T, et al. Breast cancer index identifies early-stage estrogen receptor-positive breast cancer patients at risk for early- and late-distant recurrence. Clin Cancer Res. 2013 Aug;19(15):4196-205.

45 Sgroi DC, Sestak I, Cuzick J, Zhang Y, Schnabel CA, Schroeder B, et al. Prediction of late distant recurrence in patients with oestrogenreceptor-positive breast cancer: a prospective comparison of the breast-cancer index (BCI) assay, 21-gene recurrence score, and IHC4 in the TransATAC study population. Lancet Oncol. 2013 Oct;14(11):1067-76.

46 Zhang Y, Schroeder BE, Jerevall PL, Ly A, Nolan H, Schnabel CA, et al. A Novel Breast Cancer Index for Prediction of Distant Recurrence in HR+ Early-Stage Breast Cancer with One to Three Positive Nodes. Clin Cancer Res. 2017 Dec;23(23):7217-24.

47 Sgroi DC, Carney E, Zarrella E, Steffel L, Binns SN, Finkelstein DM, et al. Prediction of late disease recurrence and extended adjuvant letrozole benefit by the HOXB13/IL17BR biomarker. J Natl Cancer Inst. 2013 Jul;105(14): 1036-42.

48 Bartlett JM, Sgroi DC, Treuner K, Zhang Y, Ahmed I, Piper T, et al. Breast Cancer Index and prediction of benefit from extended endocrine therapy in breast cancer patients treated in the Adjuvant Tamoxifen-To Offer More? (aTTom) trial. Ann Oncol. 2019 Nov; 30(11):1776-83.

49 Sanft T, Aktas B, Schroeder B, Bossuyt V, DiGiovanna M, Abu-Khalaf M, et al. Prospective assessment of the decision-making impact of the Breast Cancer Index in recommending extended adjuvant endocrine therapy for patients with early-stage ER-positive breast cancer. Breast Cancer Res Treat. 2015 Dec;154(3):533-41.

50 Foldi J, O’Meara T, Marczyk M, Sanft T, Silber A, Pusztai L. Defining Risk of Late Recurrence in Early-Stage Estrogen Receptor-Positive Breast Cancer: Clinical Versus Molecular Tools. J Clin Oncol. 2019 Jun;37(16):1365-9.

51 Lim YC, Desta Z, Flockhart DA, Skaar TC. Endoxifen (4-hydroxy-N-desmethyl-tamoxifen) has anti-estrogenic effects in breast cancer cells with potency similar to 4-hydroxytamoxifen. Cancer Chemother Pharmacol. 2005 May;55(5):471-8.

52 Borges S, Desta Z, Li L, Skaar TC, Ward BA, Nguyen A, et al. Quantitative effect of CYP2D6 genotype and inhibitors on tamoxifen metabolism: implication for optimization of breast cancer treatment. Clin Pharmacol Ther. 2006 Jul;80(1):61-74.

53 Nardin JM, Schroth W, Almeida TA, Mürdter T, Picolotto S, Vendramini EC, et al. The Influences of Adherence to Tamoxifen and CYP2D6 Pharmacogenetics on Plasma Concentrations of the Active Metabolite (Z)-Endoxifen in Breast Cancer. Clin Transl Sci. 2020 Mar;13(2):284-92.
54 Henry NL, Rae JM, Li L, Azzouz F, Skaar TC, Desta Z, et al.; Consortium on Breast Cancer Pharmacogenomics Investigators. Association between CYP2D6 genotype and tamoxifen-induced hot flashes in a prospective cohort. Breast Cancer Res Treat. 2009 Oct; 117(3):571-5

55 Dezentjé VO, van Blijderveen NJ, Gelderblom $\mathrm{H}$, Putter H, van Herk-Sukel MP, Casparie $\mathrm{MK}$, et al. Effect of concomitant CYP2D6 inhibitor use and tamoxifen adherence on breast cancer recurrence in early-stage breast cancer. J Clin Oncol. 2010 May;28(14):24239

56 Sanchez-Spitman AB, Moes DA, Gelderblom H, Dezentjé VO, Swen JJ, Guchelaar HJ. The effect of rs5758550 on CYP2D6*2 phenotype and formation of endoxifen in breast cancer patients using tamoxifen. Pharmacogenomics. 2017 Aug;18(12):1125-32.

57 Neven P, Jongen L, Lintermans A, Van Asten $\mathrm{K}$, Blomme C, Lambrechts D, et al. Tamoxifen Metabolism and Efficacy in Breast Cancer: A Prospective Multicenter Trial. Clin Cancer Res. 2018 May;24(10):2312-8.

58 Hayes DF, Rae JM. Pharmacogenomics and Endocrine Therapy in Breast Cancer. J Clin Oncol. 2020 Feb 20;38(6):525-8.

59 Goetz MP, Sangkuhl K, Guchelaar HJ, Schwab M, Province M, Whirl-Carrillo M, et al. Clinical Pharmacogenetics Implementation Consortium (CPIC) Guideline for CYP2D6 and Tamoxifen Therapy. Clin Pharmacol Ther. 2018 May;103(5):770-7.

60 Harris LN, Ismaila N, McShane LM, Andre F, Collyar DE, Gonzalez-Angulo AM, et al.; American Society of Clinical Oncology. Use of Biomarkers to Guide Decisions on Adjuvant Systemic Therapy for Women With Early-Stage Invasive Breast Cancer: American Society of Clinical Oncology Clinical Practice Guideline. J Clin Oncol. 2016 Apr;34(10): 1134-50.

61 Gradishar WJ, Anderson BO, Balassanian R, Blair SL, Burstein HJ, Cyr A, et al. Invasive Breast Cancer Version 1.2016, NCCN Clinical Practice Guidelines in Oncology. J Natl Compr Canc Netw. 2016 Mar;14(3):324-54.

62 Francis PA, Regan MM, Fleming GF, Láng I, Ciruelos E, Bellet M, et al.; SOFT Investigators; International Breast Cancer Study Group. Adjuvant ovarian suppression in premenopausal breast cancer. N Engl J Med. 2015 Jan;372(5):436-46.

63 Pagani O, Regan MM, Walley BA, Fleming GF, Colleoni M, Láng I, et al.; TEXT and SOFT Investigators; International Breast Cancer Study Group. Adjuvant exemestane with ovarian suppression in premenopausal breast cancer. N Engl J Med. 2014 Jul;371(2): 107-18.

64 Regan MM, Francis PA, Pagani O, Fleming GF, Walley BA, Viale G, et al. Absolute Benefit of Adjuvant Endocrine Therapies for Premenopausal Women With Hormone Receptor-Positive, Human Epidermal Growth Factor Receptor 2-Negative Early Breast Cancer: TEXT and SOFT Trials. J Clin Oncol. 2016 Jul;34(19):2221-31. 
65 Regan MM, Walley BA, Francis PA, Fleming GF, Láng I, Gómez HL, et al. Concurrent and sequential initiation of ovarian function suppression with chemotherapy in premenopausal women with endocrine-responsive early breast cancer: an exploratory analysis of TEXT and SOFT. Ann Oncol. 2017 Sep;28(9): 2225-32.

66 Gnant M, Mlineritsch B, Stoeger H, LuschinEbengreuth G, Knauer M, Moik M, et al.; Austrian Breast and Colorectal Cancer Study Group, Vienna, Austria. Zoledronic acid combined with adjuvant endocrine therapy of tamoxifen versus anastrozol plus ovarian function suppression in premenopausal early breast cancer: final analysis of the Austrian Breast and Colorectal Cancer Study Group Trial 12. Ann Oncol. 2015 Feb;26(2):313-20.

67 Pan K, Bosserman LD, Chlebowski RT. Ovarian Suppression in Adjuvant Endocrine Therapy for Premenopausal Breast Cancer. J Clin Oncol. 2019 Apr;37(11):858-61.

68 Francis PA, Pagani O, Fleming GF, Walley BA, Colleoni M, Láng I, et al.; SOFT and TEXT Investigators and the International Breast Cancer Study Group. Tailoring Adjuvant Endocrine Therapy for Premenopausal Breast Cancer. N Engl J Med. 2018 Jul;379(2): 122-37.

69 Kim HA, Lee JW, Nam SJ, Park BW, Im SA, Lee ES, et al.; Korean Breast Cancer Study Group. Adding Ovarian Suppression to Tamoxifen for Premenopausal Breast Cancer: A Randomized Phase III Trial. J Clin Oncol. 2020 Feb;38(5):434-43.

70 Munhoz RR, Pereira AA, Sasse AD, Hoff PM, Traina TA, Hudis CA, et al. GonadotropinReleasing Hormone Agonists for Ovarian Function Preservation in Premenopausal Women Undergoing Chemotherapy for Early-Stage Breast Cancer: A Systematic Review and Meta-analysis. JAMA Oncol. 2016 Jan; 2(1):65-73

71 Lambertini M, Moore HC, Leonard RC, Loibl S, Munster P, Bruzzone M, et al. Gonadotropin-Releasing Hormone Agonists During Chemotherapy for Preservation of Ovarian Function and Fertility in Premenopausal Patients With Early Breast Cancer: A Systematic Review and Meta-Analysis of Individual $\mathrm{Pa}$ tient-Level Data. J Clin Oncol. 2018 Jul; 36(19):1981-90.

72 van Hellemond IE, Vriens IJ, Peer PG, Swinkels AC, Smorenburg CH, Seynaeve CM, et al.; Dutch Breast Cancer Research Group (BOOG). Ovarian Function Recovery During Anastrozole in Breast Cancer Patients With Chemotherapy-Induced Ovarian Function Failure. J Natl Cancer Inst. 2017 Dec;109(12).

73 Amir E, Seruga B, Niraula S, Carlsson L, Ocaña A. Toxicity of adjuvant endocrine therapy in postmenopausal breast cancer patients: a systematic review and meta-analysis. J Natl Cancer Inst. 2011 Sep;103(17):1299-309.

74 Matthews A, Stanway S, Farmer RE, Strongman H, Thomas S, Lyon AR, et al. Long term adjuvant endocrine therapy and risk of cardiovascular disease in female breast cancer survivors: systematic review. BMJ. 2018 Oct; 363:k3845.
75 Chlebowski RT. Interpreting quality-of-life data from the SOFT and TEXT trials. Lancet Oncol. 2015 Jul;16(7):749-51.

76 Saha P, Regan MM, Pagani O, Francis PA, Walley BA, Ribi K, et al.; SOFT; TEXT Investigators; International Breast Cancer Study Group. Treatment Efficacy, Adherence, and Quality of Life Among Women Younger Than 35 Years in the International Breast Cancer Study Group TEXT and SOFT Adjuvant Endocrine Therapy Trials. J Clin Oncol. 2017 Sep;35(27):3113-22.

77 Goldvaser H, Barnes TA, Šeruga B, Cescon DW, Ocaña A, Ribnikar D, et al. Toxicity of Extended Adjuvant Therapy With Aromatase Inhibitors in Early Breast Cancer: A Systematic Review and Meta-analysis. J Natl Cancer Inst. 2018 Jan;110(1):31-9.

78 Chirgwin JH, Giobbie-Hurder A, Coates AS, Price KN, Ejlertsen B, Debled M, et al. Treatment Adherence and Its Impact on DiseaseFree Survival in the Breast International Group 1-98 Trial of Tamoxifen and Letrozole, Alone and in Sequence. J Clin Oncol. 2016 Jul; 34(21):2452-9.

79 Barron TI, Connolly R, Bennett K, Feely J, Kennedy MJ. Early discontinuation of tamoxifen: a lesson for oncologists. Cancer. 2007 Mar;109(5):832-9.

80 Hadji P, Ziller V, Kyvernitakis J, Bauer M, Haas G, Schmidt N, et al. Persistence in patients with breast cancer treated with tamoxifen or aromatase inhibitors: a retrospective database analysis. Breast Cancer Res Treat. 2013 Feb;138(1):185-91.

81 Yi M, Huo L, Koenig KB, Mittendorf EA, Meric-Bernstam F, Kuerer HM, et al. Which threshold for ER positivity? a retrospective study based on 9639 patients. Ann Oncol. 2014 May;25(5):1004-11.

82 Allison $\mathrm{KH}$, Hammond $\mathrm{ME}$, Dowsett $\mathrm{M}$, McKernin SE, Carey LA, Fitzgibbons PL, et al. Estrogen and Progesterone Receptor Testing in Breast Cancer: ASCO/CAP Guideline Update. J Clin Oncol. 2020 Apr;38(12):1346-66.

83 Pernas S, Tolaney SM, Winer EP, Goel S. CDK4/6 inhibition in breast cancer: current practice and future directions. Ther Adv Med Oncol. 2018 Jul;10:1758835918786451.

84 Dowsett M, Jacobs S, Johnston S, Bliss J, Wheatley D, Holcombe C, et al. PALLET: A neoadjuvant study to compare the clinical and antiproliferative effects of letrozole with and without palbociclib. San Antonio Breast Cancer Symposium 2018; Abstr. GS3-022018.

85 Hind D, Wyld L, Beverley CB, Reed MW. Surgery versus primary endocrine therapy for operable primary breast cancer in elderly women (70 years plus). Cochrane Database Syst Rev. 2006 Jan;(1):CD004272.

86 Eiermann W, Paepke S, Appfelstaedt J, Llombart-Cussac A, Eremin J, Vinholes J, et al.; Letrozole Neo-Adjuvant Breast Cancer Study Group. Preoperative treatment of postmenopausal breast cancer patients with letrozole: A randomized double-blind multicenter study. Ann Oncol. 2001 Nov;12(11):1527-32.
87 Mamounas EP. Facilitating breast-conserving surgery and preventing recurrence: aromatase inhibitors in the neoadjuvant and adjuvant settings. Ann Surg Oncol. 2008 Mar; 15(3):691-703.

88 Ueno T, Masuda N, Yamanaka T, Saji S, Kuroi $\mathrm{K}$, Sato N, et al. Evaluating the 21-gene assay Recurrence Score ${ }^{\circledR}$ as a predictor of clinical response to 24 weeks of neoadjuvant exemestane in estrogen receptor-positive breast cancer. Int J Clin Oncol. 2014 Aug;19(4):607-13.

89 Alba E, Calvo L, Albanell J, De la Haba JR, Arcusa Lanza A, Chacon JI, et al.; GEICAM. Chemotherapy (CT) and hormonotherapy (HT) as neoadjuvant treatment in luminal breast cancer patients: results from the GEICAM/2006-03, a multicenter, randomized, phase-II study. Ann Oncol. 2012 Dec;23(12): 3069-74.

90 Ellis MJ, Tao Y, Luo J, A’Hern R, Evans DB, Bhatnagar AS, et al. Outcome prediction for estrogen receptor-positive breast cancer based on postNET tumor characteristics. J Natl Cancer Inst. 2008;100:1380-8.

91 Ellis MJ, Suman VJ, Hoog J, Goncalves R, Sanati S, Creighton CJ, et al. Ki67 Proliferation Index as a Tool for Chemotherapy Decisions During and After Neoadjuvant Aromatase Inhibitor Treatment of Breast Cancer: Results From the American College of Surgeons Oncology Group Z1031 Trial (Alliance). J Clin Oncol. 2017 Apr;35(10):1061-9.

92 Dowsett M, Smith IE, Ebbs SR, Dixon JM, Skene A, A'Hern R, et al.; IMPACT Trialists Group. Prognostic value of Ki67 expression after short-term presurgical endocrine therapy for primary breast cancer. J Natl Cancer Inst. 2007 Jan;99(2):167-70.

93 Robertson JFR, Dowsett M, Bliss JM, et al: Peri-operative aromatase inhibitor treatment in determining or predicting long-term outcome in early breast cancer-The POETIC Trial (CRUK/07/015). 2017 SABCS, GS1-03. Available from: https://cancerres.aacrjournals.org/content/78/4_Supplement/GS1-03.

94 Gluz O, Nitz U. Christgen, et al. on behalf of the ADAPT investigators. Luminal subtypes vs. early proliferation response and Oncotype $\mathrm{DX}^{\circledR}$ in early breast cancer: Observations from the WSG-ADAPT HR+/HER2- subprotocol. 14th St.Gallen International Breast Cancer Conference 2015, The Breast 24S1 (2015) S104-S105.

95 Hurvitz SA, Martin M, Press MF, Chan D, Fernandez-Abad M, Petru E, et al. Potent Cell-Cycle Inhibition and Upregulation of Immune Response with Abemaciclib and Anastrozole in neoMONARCH, Phase II Neoadjuvant Study in HR+/HER2- Breast Cancer. Clin Cancer Res. 2020 Feb;26(3):566-80.

96 Prat A, Saura C, Pascual T, Hernando C, Muñoz M, Paré L, et al. Ribociclib plus letrozole versus chemotherapy for postmenopausal women with hormone receptor-positive, HER2-negative, luminal B breast cancer (CORALLEEN): an open-label, multicentre, randomised, phase 2 trial. Lancet Oncol. 2020 Jan;21(1):33-43. 